\title{
MANEJO DO SOLO PARA O SISTEMA DE CULTIVO DO CAFÉ NO BRASIL
}

\footnotetext{
Renato Navarro ${ }^{1}$, Alan Carlos Martelócio ${ }^{2}$, Raquel Romão Sevilha ${ }^{3}$,Graciene de Souza Bido ${ }^{4}$, Anny Rosi Mannigel ${ }^{5}$

${ }^{1}$ Pós-graduando em Fertilidade do solo e Nutrição Mineral de Plantas da Universidade Cesumar, Maringá, Paraná, Brasil.

${ }^{2}$ Pesquisador do Instituto Cesumar de Ciência, Tecnologia e Inovação da

Universidade Cesumar, Maringá, Paraná, Brasil.

${ }^{3}$ Residente Pós-mestrado do Instituto Cesumar de Ciência, Tecnologia e Inovação da Universidade Cesumar, Maringá, Paraná, Brasil.

${ }^{4,5}$ Professoras Doutoras do Departamento de Agronomia da Universidade Cesumar, Maringá, Paraná, Brasil.

E-mail: amartelocio@agronomo.eng.br
}

Recebido em: 15/11/2021 - Aprovado em: 15/12/2021 - Publicado em: 30/12/2021
DOI: 10.18677/EnciBio_2021D31
trabalho licenciado sob licença Creative Commons Attribution-NonCommercial-NoDerivatives 4.0 International License.

\section{RESUMO}

A conservação do solo é de suma importância para a sustentabilidade do sistema produtivo. Para a cafeicultura atual, o manejo deve buscar o aumento da eficiência produtiva e conservação dos recursos naturais, que aliado a utilização racional de fertilizantes e corretivos agrícolas e a manutenção da matéria orgânica do solo é fundamental para a sustentabilidade da produção. No passado houve intensa erosão e degradação de solos nas áreas ocupadas com café. A rica diversidade das áreas produtivas exige modelos de conservação e manejo que se adapte as realidades edafoclimáticas de cada microrregião, a complexidade de cada sistema produtivo determina o modelo de produção a ser desenvolvido. Sendo que em áreas onde os fatores contribuem para o aumento do processo erosivo há necessidade de envolver a integração de diferentes práticas de manejo. Por se tratar de uma planta perene as técnicas empregadas diferem do sistema de cultivo anual, a estratégia de manejo a ser adotada deve ter uma visão que se estende por toda vida útil do cultivo, a implantação deve ser bem planejada, pois uma vez estabelecida à cultura dificilmente poderá ser feita a correção de eventuais falhas.

PALAVRAS-CHAVE: Conservação, degradação do solo, fertilidade.

\section{SOIL MANAGEMENT PRACTICES FOR COFFEE FARMING IN BRAZIL: A REVIEW}

\section{ABSTRACT}

Soil conservation is of paramount importance for the sustainability of the production system. For current coffee production, management must seek to increase production efficiency and conserve natural resources, which, together with the rational use of fertilizers and agricultural correctives and the maintenance of soil organic matter, is essential for the sustainability of production. In the past, there was ENCICLOPÉDIA BIOSFERA, Centro Científico Conhecer - Jandaia-GO, v.18 n.38; p. 162 
intense erosion and soil degradation in areas occupied by coffee. The rich diversity of productive areas requires conservation and management models that adapt to the edaphoclimatic realities of each microregion, the complexity of each production system determines the production model to be developed. In areas where factors contribute to the increase in the erosive process, there is a need to involve the integration of different management practices. As it is a perennial plant, the techniques used differ from the annual cultivation system, the management strategy to be adopted must have a vision that extends over the entire useful life of the cultivation, the implantation must be well planned, as once established the culture can hardly be done to correct any flaws.

KEYWORDS: Conservation, soil degradation, fertility.

\section{INTRODUÇÃO}

A cafeicultura no Brasil tem significativa importância econômica, contribuindo com as exportações e representando um terço da produção mundial. No passado, houve grande contribuição para o desenvolvimento econômico e social no Brasil, chegando a ser o principal produto exportado. Apesar de perder representatividade, o café continua sendo um potencial gerador de empregos e faz circular uma grande quantia de dinheiro na economia. As áreas produtoras de café estão concentradas no Centro-sul do país, destacando-se os Estados de Minas Gerais, São Paulo e Paraná. De acordo com a estimativa da Organização Internacional do Café (OIC), a safra mundial desse produto entre os anos de 2011 e 2012 apresentou redução de 4,33\% em relação ao período anterior (PRIORI et al., 2012, CARVALHO et al., 2018).

Atualmente o sistema produtivo do café vem passando por um considerável aumento tecnológico. A mecanização, implantação de novas lavouras, espaçamentos adequados, variedades mais produtivas dentre outras práticas vêm contribuindo para aumento de produtividade. Porém todo o aporte tecnológico não é suficiente para garantir a sustentabilidade do sistema produtivo, quando não considerado o manejo conservacionista dos recursos naturais (HERZOG et al., 2020).

No Paraná, o café impulsionou a colonização e o desenvolvimento no século passado (PEREIRA et al., 2018). Após se tornar a maior região produtora de café do mundo, o estado passou por profundas mudanças nos sistemas produtivos, com a adoção das culturas de grãos pela prática de sucessão de culturas. A ausência de práticas sustentáveis da cadeia produtiva se deu em parte pela ineficiência da conservação dos recursos naturais, que resultou na degradação das lavouras, além da perda do potencial produtivo pela ocorrência de geadas, que ocasionaram o maior impacto nas lavouras cafeeiras, sendo necessária sua erradicação.

Com o advento do plantio direto e outras práticas de conservação no Paraná, os agricultores puderam manejar o solo com maior eficiência, porém os cafeicultores, com sua lavoura já implantada, tiveram dificuldades em estabelecer práticas conservacionistas eficientes, o que contribuiu para a queda de produção ao longo dos anos. Com isso, outros estados conseguiram melhor adaptação para o sistema de manejo do café, onde pode se estabelecer com maior eficiência, pois este novo sistema de produção com maior aporte tecnológico possibilitou aumento na produtividade e redução de perdas, otimizando o processo de sustentabilidade do sistema. 
O debate atual sobre a sustentabilidade da agricultura no Brasil aponta desafios futuros e preocupações acerca do sistema de cultivo do café, alinhando com a necessidade de geração e distribuição de renda para todas as famílias rurais envolvidas no processo, bem como a garantia de acesso à infraestrutura e aos serviços sociais que condicionam a cidadania, no limite da capacidade de suporte ambiental, sem comprometer as condições de dignidade para as gerações futuras. A cafeicultura brasileira apresenta uma rica diversidade de modelos de produção, devido à diversidade das áreas de cultivo. As regiões montanhosas, sul de minas (VILAS BOAS, 2020), zona da mata e Espírito Santo, são responsáveis por expressiva parcela da produção, e ainda traz um modelo tradicional de cultivo, por sua dificuldade de mecanização. Muitas alternativas têm surgido para essas regiões, onde a declividade do terreno é acentuada. Além da dificuldade de eficiência na produção, existe a preocupação em torno da conservação dos solos, que em alguns casos, ultrapassam $40 \%$ de declividade. Não se pode, entretanto, restringir essas áreas de produção, pois sua importância não está somente no produto, mas no impulso da economia regional e geração de empregos que é de grande relevância para a sociedade nestes locais.

O Cerrado Mineiro, Alta Mogiana e Oeste da Bahia tem se destacado no desenvolvimento de tecnologias de produção. Essas áreas, a mecanização tem maior difusão, pois o relevo tem predominância de menor declividade, preconizando técnicas de conservação relativamente simples podem ser suficientes para conservação do solo.

Vários fatores interferem para o resultado positivo da cafeicultura. Um conjunto de condições determina o sucesso das lavouras, destacando-se os fatores econômico e qualitativo, no qual englobam a redução dos custos de produção, o aumento na produtividade, a busca por qualidade, a preservação dos recursos naturais e a promoção da sustentabilidade, a abertura de novos mercados consumidores, e a adoção de estratégias e políticas públicas para o desenvolvimento da cadeia produtiva do café. Quanto à definição de políticas agrícolas para o setor cafeeiro, é relevante considerar o estabelecimento de um sistema de previsão de safra eficiente e objetivo que atenda às necessidades de planejamento e de comercialização, para evitar que o agronegócio do café fique à mercê dos especuladores internos e externos (ZAMBOLIM, 2001).

$A$ área de produção e café no Brasil é relativamente pequena, quando comparada a sua área agricultável total. Esta cultura apresenta restrições climáticas, se no Paraná, São Paulo e Sul de Minas há o risco de geada, outras regiões possuem restrições hídricas moderadas ou severas. Há também a competição por área entre as culturas, muitas áreas aptas para a produção estão ocupadas por outros sistemas de cultivo.

Diante da situação exposta, esta revisão de literatura pretende apresentar e discutir pontos relevantes sobre o manejo do solo aplicado a cultura do café, abordando o que se discutiu e vem sendo discutido, com o intuito de contribuir com a sustentabilidade do manejo do solo para o café no Brasil. A revisão é composta, além desta parte introdutória, de mais oito seções, que trazem pontos sobre aspectos agronômicos do solo e do café, distribuídos em conservação, degradação, fertilidade e nutrição e outros parâmetros. 


\section{A cultura do café e os aspectos agronômicos do solo}

O cafeeiro (Coffea arabica L.) é uma planta originária dos altiplanos da Etiópia, próxima à linha equatorial, variando a latitude entre $6^{\circ}$ a $9^{\circ} \mathrm{N}$ e longitudes $34^{\circ}$ a $40^{\circ} \mathrm{E}$, de 1600 a 1900 metros de altitude, com temperaturas de $17^{\circ}$ a $20^{\circ} \mathrm{C}$, onde cresce permanentemente sob o sombreamento em habitat de floresta tropical. Tem uma estação seca definida de 3 a 4 meses e precipitações pluviais anuais entre 1200 a $2000 \mathrm{~mm}$ bem distribuídos durante o restante do ano e ainda, cresce espontaneamente em ambiente de sub-bosques de florestas, onde se adaptou a baixa intensidade de radiação solar, temperaturas amenas e ausência de geadas (LUNZ et al., 2005).

A fenologia do café compreende uma sucessão de fases vegetativas e reprodutivas, ocorrendo num período de 2 anos, diferentemente do que ocorre com a maioria das plantas, com inflorescência na primavera e frutificam no mesmo ano fenológico (CAMARGO; CAMARGO, 2001). Durante as fases fenológicas do cafeeiro as condições ambientais afetam diretamente seu desenvolvimento. A topografia e suas variações (latitude, longitude) determinam a atuação do fotoperíodo, provocando consequências no ciclo da cultura. Quando da combinação de altitude e longitude, ambas condicionam variações meteorológicas distintas, acometendo os regimes térmicos e tendo reflexão na produtividade e na qualidade da bebida (DAMATTA, 2004).

$O$ café possui sistema radicular pivotante que chega a explorar $1,50 \mathrm{~m}$ de profundidade, exigindo assim, solos mais profundos, sendo mais indicado o cultivo em Latossolos e Argissolos. As condições naturais do solo podem limitar o enraizamento em profundidade do cafeeiro por ocorrência de rochas, adensamento, condições hídricas e químicas e por teores elevados de alumínio e sódio, podendo ainda ser induzido à compactação pela ação antrópica (FERNANDES, 2018).

Os solos intemperados, como os latossolos, não apresentam um arranjo que permita maior estruturação deste solo, sendo presente pequenos grânulos soltos com grande espaço poroso, colocando o solo em situação de susceptibilidade aos processos erosivos. A atividade biológica é importante nestas condições para a estruturação do solo, pois as raízes e a fauna edáfica movimentam partículas, e estas mais juntas, tendem a formar agregados, além de criar poros. Da decomposição da matéria orgânica, as bactérias liberam polissacarídeos que criam agregados estáveis em água ao se ligar com a fração mineral do solo (MACHADO et al., 2020; MARCATTI et al., 2020).

Siqueira et al. (2014) verificaram que os diferentes métodos de controle das plantas invasoras influenciaram a estabilidade de agregados no solo, a argila dispersa em água, o índice de floculação e matéria orgânica do solo. Ainda, observou que nos métodos de controle realizado com grade e herbicidas préemergente apresentou os menores índices de estabilidade de agregados proporcionando a maior suscetibilidade aos processos erosivos.

\section{Aptidão agrícola para a cafeicultura}

A sustentabilidade do desenvolvimento de um sistema econômico está diretamente vinculada à preservação dos recursos naturais. Na agricultura o uso destes recursos deve respeitar limites absolutos de sua capacidade, de acordo com as condições encontradas em cada ambiente. Para avaliar o potencial das terras foram criados diversos sistemas, sendo a capacidade de uso um os mais adotados 
no Brasil (SANTOS et al., 2018). A partir desta classificação pode-se definir o uso do solo e estabelecer a melhor estratégia de manejo e conservação .

As classificações técnicas ou interpretativas de aptidão agrícola agrupam solos de acordo com interesse prático e específico em relação ao seu comportamento. Através da avaliação dos fatores limitantes como fertilidade, água, oxigênio, suscetibilidade a erosão e restrições a mecanização pode-se definir o melhor uso do solo, extraindo seu potencial máximo, minimizando a degradação.

No Brasil, a cafeicultura ocupa cerca de 2,19 milhões de hectares, espalhados ao longo de seu território. Nas últimas décadas, tem mostrado decréscimo na área plantada, apesar do aumento da produção, que é reflexo da adoção de tecnologia nas práticas de manejo do café (CONAB, 2021). O Paraná tem capacidade de produzir café com sustentabilidade, adotando técnicas de manejo adequadas e através da introdução das tecnologias presentes em outras regiões, sendo adaptadas as realidades da região para se produzir satisfatoriamente.

O planejamento e uso ambiental de extração de recursos naturais necessita do conhecimento relativo à ocupação do homem e a importância das atividades realizadas para a sociedade, bem como da biodiversidade e valor ecológico da região. Para estabelecer o melhor uso da ocupação das terras faz-se necessário informações relativas às características do espaço geográfico referido, utilização de técnicas como geoprocessamento e levantamento a campo são importantes no desenvolvimento de modelo de uso e ocupação das terras buscando melhor aproveitamento dos recursos naturais com mínimo impacto ambiental (BERTOLDO, 2008).

\section{Preparo do solo}

O preparo de solo para a cultura do café bem como sua implantação envolve uma série de aspectos que devem ser minuciosamente analisados. Se tratando de uma cultura perene, após o seu estabelecimento, há grandes dificuldades na correção. Pequenos detalhes podem comprometer a longevidade da lavoura, a qualidade do produto, a produtividade e os custos de produção, tendo por consequência direta, a redução na rentabilidade (PARECIDO, 2020).

O objetivo do preparo de solo é melhorar as características químicas, físicas e biológicas do solo, para o favorecimento do desenvolvimento da cultura a ser implantada. Nas linhas de plantio do café, é recomendado o preparo profundo do solo, para eliminar condições desfavoráveis que possam limitar o desenvolvimento radicular. Devendo ainda ser levado em consideração as práticas de conservação, sendo recomendada a incorporação de insumos minerais e orgânicos no sulco de plantio, com base nos níveis de fertilidade do solo (DINIZ et al., 2019).

O desenvolvimento da mecanização na cafeicultura contribuiu para o aumento da capacidade produtiva dos agricultores, porém o intenso tráfego de máquinas tem comprometido a estrutura física de alguns solos, principalmente pela realização de operações em condições inadequadas. A compactação gerada pode reduzir a produtividade da área e comprometer a conservação do solo (SILVA et al., 2006, LANI et al., 2019).

\section{Degradação do solo e processos erosivos no cafeeiro}

A degradação do solo pode ser entendida como a perda da capacidade do solo em desempenhar uma função específica, afetando sua capacidade produtiva e 
a sustentabilidade do ecossistema. Dentre os processos de degradação, ocorrem a perda dos horizontes superficiais, deformação do terreno e movimento de partículas através da erosão hídrica e eólica; empobrecimento químico pela redução dos níveis de nutrientes, diminuição da matéria orgânica, salinização, acidificação e poluição; problemas físicos como compactação, selamento, baixa aeração, inundação, excesso ou falta de água; redução da biomassa e biodiversidade. A falta de conhecimento relativo aos recursos naturais no desenvolvimento da atividade humana, influência as propriedades do solo tornando-o mais suscetível ao processo erosivo quando o uso e manejo do solo são inadequados (HERNANI, 2002).

De acordo com Gonçalves (2019), Zacarias e Souza (2019), que conceituaram área degradada como aquela que apresenta solos empobrecidos e erodidos, instabilidade hidrológica, produtividade primária e diversidade biológica reduzidas. De forma geral, aquele solo que apresenta desequilíbrio nos atributos físicos, químicos e biológicos. Para Padovan et al. (2019), a agricultura convencional tem potencial elevado como fator de degradação do ambiente, por ser a principal causa de desmatamento e destruição das florestas, redução da capacidade produtiva dos solos, assoreamento dos rios, contaminação das águas por agroquímicos e redução da biodiversidade. Entre as práticas e técnicas difundidas nas áreas agrícolas que causam impactos no meio ambiente, estão: o cultivo intensivo do solo, a adição de fertilizantes, a irrigação, o uso de agrotóxicos e a manipulação dos genomas das plantas (ZACARIAS; SOUZA, 2019).

O processo de erosão do solo ocorre naturalmente, entretanto, sua intensidade geralmente é menor do que a formação do solo. Com a interferência do homem, removendo a vegetação nativa e realizando preparo do solo para a produção agrícola, a intensidade da erosão pode aumentar drasticamente, intensificada pelo preparo convencional do solo. O conhecimento do potencial erosivo de cada localidade é importante para o planejamento conservacionista e o uso agrícola do solo.

Tem-se possibilidade de controlar o processo erosivo em determinadas áreas com técnicas menos invasivas, como a manutenção da cobertura do solo e aumento da taxa de matéria orgânica do solo. Quando há fatores que contribuem para a erosão devem-se adotar outras técnicas e manejo do solo. Com a reorganização do escoamento superficial pela construção de terraços e canais de escoamento; criação de barreiras físicas, cultivos em nível, cordões de vegetação permanente, cultivo em faixas, patamares e banquetas; reconstituição do solo pelo sistema de plantio direto, correção da fertilidade química, descompactação, cobertura vegetal e cobertura morta.

Os serviços ecossistêmicos podem ser fornecidos pelo crescimento dos agroecossitemas. É evidente a necessidade reduzida de insumos externos, com a aplicação de manejo que promovam processos ecológicos para melhorar a qualidade do solo, a sustentabilidade do próprio sistema e consequentemente a produtividade das culturas inseridas e adaptadas a esse modelo (ALTIERI; NICHOLLS, 2017; PALOMO-CAMPESINO, 2018).

Alcântara e Ferreira (2000) verificaram que os diferentes métodos de controle das plantas invasoras alteraram significativamente os indicadores de qualidade física no solo nas camadas de $0-15$ e de $15-30 \mathrm{~cm}$. Sendo que a utilização de herbicida pré-emergente reduz o teor de matéria orgânica enquanto uso de enxada rotativa promoveu a compactação subsuperficial. 
O sistema de manejo nas entre linhas do cafeeiro com braquiária (Uroclhoa $s p$.) como planta de cobertura, promoveu alterações físicas e de retenção de água na camada de $0-20 \mathrm{~cm}$ promovendo aumento de $18 \%$ na água disponível do solo. Esse aumento pode ser associado à agregação promovida pelas raízes da braquiária (ROCHA et al., 2014).

A erosão hídrica do solo é o resultado da interação entre os fatores potencial erosivo da chuva, suscetibilidade do solo à erosão (erodibilidade), comprimento da rampa, declividade do terreno, manejo do solo, de culturas e de restos culturais; além das práticas conservacionistas do solo, sejam elas mecânicas, vegetativas ou edáficas (ZACARIAS; SOUZA, 2019). As práticas conservacionistas permitem o controle de perdas de solo e da água em áreas agriculturáveis, com o objetivo de tornar o processo mais sustentável e deixar o solo em sua capacidade produtiva, maximizando a rentabilidade sem provocar redução da capacidade produtiva.

A importância da manutenção de diferentes regiões de cultivo no Brasil está ligada a logística e ao volume da produção cafeeira. Os eventos climáticos regionais que reduz a produção são compensados pela produção de outra, e ao atendimento de mercados específicos dos cafés especiais, já que cada região produz um produto com características únicas.

Em cada região é preciso ter conhecimento das condições do solo e sua respectiva interação com as características climáticas. $\mathrm{O}$ cultivo deve estar adaptado as determinadas condições para otimização da eficiência produtiva, sem que haja comprometimento da conservação dos recursos naturais.

$\mathrm{Na}$ ausência de cobertura morta ou vegetal, além da ações das raízes fixadoras, o solo fica exposto ao impacto direto da chuva ou do vento, sofrendo desagregação, chamado de efeito "splash" - fluxo turbulento, ocorrendo posteriormente 0 arraste das partículas pela enxurrada. Este efeito é complementado pelo escoamento superficial das águas, ou pela dispersão das partículas pelo vento (SOUZA, 2018).

As práticas de conservação de solo aliadas ao uso de práticas agrícolas sustentáveis são fundamentais para a recuperação de áreas em situação de degradação. Tais práticas incluem: análise de solo; terraceamento, rotação de cultura, plantio em nível, cobertura vegetal e consorciação. Com ações integradas e conjuntas, as técnicas de proteção do solo, tanto vegetativas como mecânicas, buscam conservar e recuperar solos degradados pela ação do homem. A adoção de sistemas de produção ou de práticas conservacionistas de solo e água devem ser feitas em concomitância aos aspectos ambientais e socioeconômicos de cada propriedade e região.

\section{Conservação do solo para o cafeeiro}

As áreas de produção localizadas em maior declividade e em região com regime hídrico elevado, exige sistema de conservação de maior complexidade, adotando um conjunto de práticas que se adaptam a condição local. Já em locais e relevo com baixa declividade é possível produzir com práticas de conservação relativamente simples.

Diversos métodos de manejo de solo e técnicas de conservação podem ser aplicados no processo produtivo. O uso inadequado pode comprometer suas características químicas e físicas, podendo inutilizá-lo permanentemente. A utilização de técnicas inadequadas de cultivo, como o plantio no sentido do declive pode 
contribuir para o processo erosivo. A manutenção da cobertura do solo com plantas para essa finalidade é uma alternativa para conservação do solo, pois a maior taxa de perda no solo ocorre em função dos baixos níveis de cobertura.

Para Souza (2018), a conservação do solo e da água, difundida pelo manejo, recomendam se práticas conservacionistas fundamentadas em três princípios básicos: a) aumento da cobertura vegetal (reduz a desagregação e transporte de partículas do solo); b) infiltração de água no solo (reduz o escoamento superficial e as perdas de água e solo); e c) rugosidade do terreno (reduz a velocidade e o volume do escoamento superficial e aprisiona os sedimentos da erosão).

No passado a construção de terraços foi um avanço na conservação do solo, mas apesar da redução na erosão, em muitos casos a técnica se mostrou insuficiente, visto que muitos solos traziam problemas como a compactação. A introdução do plantio direto ajudou na maior parte destes problemas relativos à conservação. Nas culturas perenes a dificuldade encontrada inicialmente na conservação vem sendo superadas com êxito nos cultivos com maior aporte tecnológico. A manutenção da massa verde ou seca nas entrelinhas trouxe benefícios comparados ao plantio direto nas culturas anuais.

Assim, o manejo da vegetação nas entrelinhas é de fundamental importância para a proteção do solo contra o processo erosivo, mantendo o solo sempre protegido, com plantas ou resíduo vegetais. As plantas invasoras, quando bem manejadas, podem ser benéficas no sistema produtivo, através da camada de cobertura formada sobre o solo, protegendo contra a erosão, compactação e impacto da gota da chuva; proporcionando melhor equilíbrio térmico, infiltração, manutenção da umidade, aumento da ciclagem de nutrientes, aumento da matéria orgânica, biodiversidade no solo (DINIZ, 2019).

A sustentabilidade da produção agrícola depende diretamente do uso racional e conservador dos recursos naturais, sendo cada vez mais relevantes a conservação o solo e da água para manutenção do sistema produtivo (ARAÚJO et al., 2007). Há exigência de eficiência, qualidade, preservação e melhoria no ambiente, nos processos de produção agrícola. Dentro desse padrão, os modelos tecnológicos de produção cafeeira devem ser adaptados (BRACCINI et al., 2002).

A fertilidade do solo apresenta uma dinâmica na qual sofre influência pelo manejo da agricultura moderna. Há frequente exportação pelas colheitas e podem ocorrer perdas por erosão e lixiviação, além dos processos de fixação de $P$ em alguns tipos de argila. Dentro desses sistemas, temos ainda que considerar os processos simultâneos de imobilização e liberação de nutrientes por microrganismos. Por ser um sistema aberto, o balanço dos nutrientes nunca é estável (COSTA et al., 2020).

Cogo et al. (2003), verificaram o efeito da fertilidade sobre a perda de solo pelo processo erosivo. O solo com baixa fertilidade teve aumento de aproximadamente $200 \%$, de perda, em relação ao solo de fertilidade corrigida. Concluíram que aumento de fitomassa das culturas e em consequência, os resíduos culturais garantiram melhor cobertura do solo.

Segundo Stefanoski et al. (2013), a estrutura do solo determina o comportamento dos processos que ocorrem no solo, sendo sensível as práticas de manejo. Geralmente, sob vegetação nativa, o solo apresenta características estruturais adequadas ao bom desenvolvimento das plantas. Entretanto, o uso agrícola pode causar alterações adversas nos atributos como densidade, 
porosidade, estabilidade dos agregados infiltração, retenção de água e aeração; podendo prejudicar o crescimento vegetal.

O manejo do solo tem influência direta na porosidade do solo, afetando assim a infiltração e a dinâmica da água, principalmente na absorção pelas plantas. Trabalhos que mostram a avaliação e o impacto do manejo e como podem afetar a distribuição dos poros e a condutividade hidráulica é de grande relevância para as práticas agrícolas para remediar os efeitos do estresse hídrico (SILVA et al., 2021).

A matéria orgânica do solo é considerada o dos principais elementos da formação e estabilização dos agregados, o que foi evidenciado em vários estudos dessa linha (TROLEIS et al., 2017; GHOSH et al., 2018; SOARES et al., 2019; SILVA et al., 2021).

\section{Exigências nutricionais do cafeeiro}

A produtividade sustentável das culturas e a otimização do uso eficiente dos nutrientes dependem de uma série de fatores de produção que devem ser manejados de forma integrada, dentre os quais se destacam: analise do solo e de plantas, preparo adequado do solo, controle de pragas, doenças e plantas daninhas, nível adequado de matéria orgânica e, principalmente, manejo adequado dos fertilizantes (disponibilidade de nutrientes na solução do solo em contato com o sistema radicular da planta).

Há variação de exigência mineral pelas plantas de Coffea arabica durante o ano e também de um ano para outro. A planta de café leva dois anos para completar seu ciclo fenológico, onde que, no primeiro ano ocorre a estruturação vegetativa pela formação de ramos e gemas, e no segundo ano, ocorrem floração e a formação de frutos. Há importância de conhecer seu ciclo, para identificar o período de maior demanda de nutrientes pela planta, e assim definir método mais eficiente nas práticas de adubação. O nitrogênio é o elemento utilizado em maior quantidade pelo cafeeiro, em solos tropicais normalmente ocorre deficiência nos cultivos. Grande importância no manejo da adubação, principalmente nos períodos chuvosos. As doses recomendadas variam de 50 a $450 \mathrm{~kg}$ de $\mathrm{N} / \mathrm{ha}$, foi encontrada maior produtividade em dose $210 \mathrm{~kg}$ de N/ha. (LAVIOLA et al., 2007).

A qualidade e a produção da cultura do café são determinantes quando se pensa em adubação. Com isso, o entendimento do uso eficiente dos fertilizantes, a absorção e taxa nutricional das raízes e folhas, e da utilização desses pelas plantas para a transformação em produto agrícola é uma exigência fundamental para a sustentabilidade do sistema produtivo (FAVARIN, 2013; MATTOS JUNIOR et al., 2018).

Os processos moleculares, bioquímicos e fisiológicos das plantas estão intimamente relacionados a eficiência do uso de adubos e adubações, e como procede o uso dos nutrientes que são absorvidos. As respostas que as plantas ao uso de fertilizantes também estão associadas a absorção, ao transporte até a parte aérea, assimilação e redistribuição dos nutrientes para os orgãos-drenos. No café, ainda que não seja muito comum o porta-enxertos, verificaram-se características contrastantes para diferentes materiais de Coffea arabica e C. canefora quanto a absorção e eficiência de utilização de fósforo (FAVARIN, 2013; MATTOS JUNIOR et al., 2018).

O estado nutricional das plantas e alguns parâmetros de fertilidade como disponibilidade de fósforo e potássio no solo, a produtividade estimada e realizada, 
manejo e fertilidade do solo, presença de plantas invasoras, além de outras características, embasam o manejo de nitrogênio, fosforo e potássio nas lavouras cafeeiras e a programação para aplicação das doses de reposição de nutrientes. Para a cultura do café, as doses de nitrogênio recomendados para plantações bastantes produtivas podem chegar a $450 \mathrm{~kg} / \mathrm{ha}$ de $\mathrm{N}$, enquanto para potássio as doses podem chegar a $400 \mathrm{~kg}$ há $^{-1}$ de $\mathrm{K}_{2} \mathrm{O}$. Para fósforo, na faixa de 60 a $80 \mathrm{~kg} / \mathrm{ha}$ de $\mathrm{P}_{2} \mathrm{O}_{5}$ (FAVARIN, 2013; MATTOS JUNIOR et al., 2018).

O fósforo é essencial visando o desenvolvimento das plantas perenes, pois têm menor resposta de $\mathrm{P}$ na produção em relação às culturas anuais. Trata-se de um dos macronutrientes menos exportado pelo café, e atua diretamente no desenvolvimento inicial das plantas. Em solos de baixa fertilidade, foi encontrada resposta na produção com 0 aumento a dose aplicada de fósforo. No solo, o $\mathrm{P}$ apresenta uma complexa dinâmica que pode limitar sua disponibilidade para as plantas e reduzir a eficiência da adubação (ALMEIDA et al., 2012).

O potássio é exigido pelo cafeeiro tanto quanto o nitrogênio. Tem influência na formação do grão e desempenha importante função na translocação de fotoassimilados, que contribui para o aumento de peso, volume, qualidade da bebida, resistência a doenças e resistência ao estresse hídrico (MANCUSO, 2014).

Segundo Prezotti (2001), há três métodos de estimativa de necessidade de calcário: a) o que visa suprir a necessidade da planta em $\mathrm{Ca}$ e $\mathrm{Mg}$; b) elevar a saturação por base para $60 \%$ sempre que estiver abaixo de $50 \%$; c) e o método que se baseia na neutralização do Al. O gesso é recomendado para elevar o $\mathrm{Ca}$ em subsuperfície ou neutralização de Al.

O enxofre está relacionado diretamente com a matéria orgânica no solo, sendo maior problema em solos degradados. No cafeeiro a exigência de $S$ é semelhante à de $\mathrm{P}$. Os aminoácidos sulfurados, junto com os açucares, são responsáveis pelas características organolépticas do café, portanto a deficiência de $S$ pode comprometer a qualidade final do café (PAIVA, 2008).

Estudando fertilização orgânica, Espinoso et al. (2019) observaram que no sistema consorciado houve maiores incrementos na fertilidade química do solo nos cultivos de ambas as espécies de café. Também observaram que a adubação orgânica proporciona melhoras nas espécies analisadas, nos teores dos elementos relacionados a fertilidade química em ambos os sistemas analisados e nos solos onde houve cultivo com esse tipo de adubação. Os elementos $\mathrm{Mo}, \mathrm{Mg}$ e B ficaram abaixo do nível crítico nos solos analisados. Por fim, concluíram que a ferramenta fertigramas foram fundamentais na interpretação da fertilidade química do solo avaliando a demanda mínima dos cafeeiros (níveis críticos) e os resultados das análises dos solos.

Além da produtividade a nutrição da planta interfere na qualidade final do café, atributo que interfere diretamente no preço do produto. Tanto pelas substâncias químicas que são acumuladas no grão durante seu desenvolvimento e maturação, quanto pela incidência de microrganismos nas fases de pré-colheita e pós-colheita. Sendo que as plantas com desequilíbrio nutricional tendem a ter menor resistência aos ataques de microrganismos (MARTINEZ et al., 2014).

As maiores concentrações médias de nitrogênio em águas de escoamento superficial foram de nitrato $(2,422 \mathrm{mg} / \mathrm{L})$ e "outras formas" $(2,423 \mathrm{mg} / \mathrm{L})$ e a menor concentração média foi de nitrito $(0,320 \mathrm{mg} / \mathrm{L})$. Para as concentrações de $P$ total e ortofosfato, apresentaram valores semelhantes $(>2,0 \mathrm{mg} / \mathrm{L})$, sendo mais visíveis na 
forma inorgânica. As perdas de $\mathrm{N}$ e $\mathrm{P}$ foram maiores em dias de elevado escoamento superficial. As perdas de $N$ e $P$ das parcelas experimentais apresentaram baixa correlação com o escoamento superficial. Os resultados alcançados no estudo concluem que áreas plantadas com café podem ser consideradas importantes fontes de $\mathrm{N}$ e $\mathrm{P}$ para sistemas aquáticos adjacentes, quando ocorrem altas taxas de escoamento superficial. Assim, a adoção de práticas conservacionistas como o plantio em nível em conjunto como a roçagem, acompanhadas de uma adubação fracionada no decorrer do ano são recomendadas para reduzir o escoamento superficial e minimizar as perdas desses nutrientes.

A qualidade na produção de café é valorizada quando o cafeicultor, no objetivo de obter preços diferenciados, entre os produtos classificados como especiais, diferenciados e comerciais agrega valor à sua produção. Fatores como adubação, variedade do café, clima local, processamento pós-colheita influenciam na qualidade do grão.

O elemento potássio tem elevado consumo por parte da planta de café, principalmente durante a formação do grão, o que atribui a garantia de um produto de melhor qualidade. A fonte do fertilizante por meio da qual ele é fornecido às plantas é um importante caminho para que possa atingir a qualidade satisfatório. Adubações com sulfato ou nitrato de potássio são mais indicadas para incrementar o tamanho e o teor de açúcares nos grãos, bem como melhorar a qualidade da bebida, enquanto o suprimento de potássio com a utilização exclusiva de cloreto de potássio não é interessante, uma vez que o cloro diminuiu a qualidade dos grãos (MATTOS JUNIOR et al., 2018).

No preparo de solo para o estabelecimento de novos cafezais, a manutenção de níveis adequados de saturação por bases (V\%) é importante, pois nessa etapa, o investimento na aplicação de calcário em profundidade no sulco de plantio, com a adição de fósforo e zinco, garante a boa formação inicial das plantas. O uso de gesso é importante e segue recomendações no manejo inicial do café, com doses de até 2 t/ha em solos mais argilosos (FAVARIN, 2013; MATTOS JUNIOR et al., 2018).

\section{Matéria orgânica}

Técnicas implantadas nos últimos anos vêm contribuir para melhorar a utilização dos solos, como a integração-lavoura-pecuárias-floresta, o plantio direto e a intensificação sustentável do uso do solo, graças aos avanços das pesquisas sobre correção e adubação do solo possibilitaram aumentos de produção nas áreas cafeeiras, tornando férteis e aptas à produção, minimizando os impactos dos desequilíbrios das relações físicas, químicas e biológicas do solo.

A utilização de adubação com compostos orgânicos pode reduzir a densidade do solo diminuindo problemas com a compactação. É uma alternativa viável, pois em lavouras já implantadas, problemas com compactação não podem ser resolvidos com ação mecânica. A aplicação de palha de café, capim, cama de frango e outros materiais orgânicos podem ser uma alternativa viável para amenizar a compactação, além de aumentar o estoque de carbono e fornecer nutrientes para as plantas (SILVA et al., 2015).

Além desta estratégia, o manejo da entrelinha, com a utilização de braquiárias como cultura de cobertura, aliada ao uso da roçadeira ecológica, a qual deposita a palha da biomassa produzida na entrelinha sobre a linha de plantio, contribui na manutenção da umidade e temperatura do solo, as quais são fundamentais para o 
desenvolvimento das raízes. O incremento da palha sobre o solo favorece também a manutenção ou o aumento da matéria orgânica, a qual proporciona maior fertilidade e condições mais favoráveis para o bom desenvolvimento do sistema radicular (CAMPOS, 2018).

Diversas pesquisas indicam que a utilização de adubação verde associada com a espécie Coffea arábica L. não tem efeito benéfico, ou ainda pode ser prejudicial. No entanto, diversos autores citam que, após prejuízos iniciais acometidos na execução desta prática, obtiveram-se acréscimos produtivos no médio e longo prazo (CAMPOS et al., 2018; PEREIRA et al., 2020).

\section{CONSIDERAÇÕES FINAIS}

A conservação do solo é uma das técnicas importantes na cafeicultura, além de ser um dos desafios atuais e futuros do segmento, no sentido de produzir com qualidade e com sustentabilidade. Visando otimizar as técnicas de cultivo, a sustentabilidade do sistema deve ser encontrada para manter o solo na sua capacidade produtiva.

É importante a disseminação e adoção de tais práticas, levar o conhecimento e o entendimento ao produtor rural para que ele possa praticar de forma correta e assim dar suas contribuições. Sustentabilidade rural deve ser abordada com maior ênfase. É possível ter lucratividade no campo com adoção de ações conservacionistas.

\section{REFERÊNCIAS}

ALCÂNTARA, E. D., \& FERREIRA, M. M. Efeitos de métodos de controle de plantas daninhas na cultura do cafeeiro (Coffea arabica L.) sobre a qualidade física do solo. Revista Brasileira de Ciência do Solo, 24, 711-721. 2000.

ALMEIDA, L. H. C., KLEIN, P. H., DE OLIVEIRA, E. C., \& MIGLIORANZA, E. Silício e disponibilidade de fósforo no crescimento e desenvolvimento de mudas de café. Revista Cultura Agronômica, v. 26, n. 2, p. 123-131, 2017. Disponível em: https://doi.org/10.32929/2446-8355.2017v26n2p123-131

ALTIERI, M. A.; NICHOLLS, C. I.; O potencial de adaptação e mitigação da agricultura tradicional em um clima em mudança. Mudança climática, v. 140, n. 1, pág. 33-45, 2017.

ARAÚJO, R.; GOEDERT, W.J.; LACERDA, M.P.C. Qualidade de um solo sob diferentes usos e sob cerrado nativo. Revista Brasileira de Ciência do Solo, Viçosa, v. 31, n. 5, p. 1099-1108, 2007.

BRACCINI, M.C.L.; BRACCINI, A. de L.; SCAPIM, C.A.; FILHO, P.S.V.; ZABINI, A.V. Produção de grãos, concentração e aproveitamento de nutrientes em resposta ao aumento na densidade de plantio do cafeeiro. Acta Scientiarum Agronomy, Maringá , v. 24, n. 5, p. 1205-1211, 2002

CAMARGO, Â. P.; CAMARGO, M. B. P. Definição e esquematização das fases fenológicas do cafeeiro arábica nas condições tropicais do Brasil. Bragantia, v. 60, p. 65-68, 2001. https://doi.org/10.1590/S0006-87052001000100008 
CAMPOS, S. DE A.; LANA, R. DE P.; GALVÃO, J. C. C.; COELHO, S. P.; TROGELLO, E.; TAVARES, V. B.; SOUZA, M. N.; VELOSO, C. M. Uso de cama aviária na produção de milho e qualidade da silagem. Revista Brasileira de Milho e Sorgo, v.16, p. 373-387, 2018. DOI: https://doi.org/10.18512/1980-6477/rbms.v16n3p373-387

CARVALHO, A. C., CARVALHO, D. F., FILGUEIRAS, G. C., ARAÚJO, A. C. D. S., \& DE CARVALHO, A. V. Panorama e importância econômica do café no mercado internacional de commodities agrícolas: uma análise espectral. Revista Agroecossistemas, v. 9, n. 2, p. 223-249, 2018. Disponível em: http://dx.doi.org/10.18542/ragros.v9i2.5003

COGO, N. P., LEVIEN, R., \& SCHWARZ, R. A. Perdas de solo e água por erosão hídrica influenciadas por métodos de preparo, classes de declive e níveis de fertilidade do solo. Revista Brasileira de Ciência do Solo. 2003, v.27, n.4, pp.743753. ISSN 1806-9657. Disponível em: https://doi.org/10.1590/S0100-06832003000400019

CONAB. Companhia Nacional de Abastecimento. Acompanhamento safra brasileira café, v. 8, safra 2021, no1 primeiro levantamento, janeiro 2021.

COSTA, T. L., BORGES, L. S., MELO MOURA, W., CAVALCANTE, V. S., JACOB, L. L., \& FREITAS, M. A. S. Fertilidade do solo em sistemas de cultivo arborizados de café arábica. Cadernos de Agroecologia, 15(1). 2020.

DAMATTA, F. M. Limitações ecofisiológicas na produção de café sombreado e não sombreado: uma revisão. Pesquisa de safras de campo , v. 86, n. 2-3, pág. 99-114, 2004. https://doi.org/10.1016/j.frr.2003.09.001

DINIZ, C.V.C.; MARTINS NETO, F. L. M. \& VIVIANI, M. J. Manual do Café Orgânico. $1^{\circ}$ Edição. Piracicaba: Agrobiota, 2019.

ESPINOSO, Q. S.; SIMÃO, J. B. P.; PELUZIO, J. B. E.; RANGEL, O. J. P. Fontes e localização de fósforo no crescimento de mudas de café catuaí vermelho IAC 44. Alegre - ES. Cafeicultura no Caparaó. Resultados de Pesquisas III, Instituto Federal de Educação, Ciência e Tecnologia do Espírito Santo, 2019

FAVARIN, J. L.; TEZOTTO, T.; PAULA NETO, A. Balanço nutricional em café: estudo de caso. 2013.

FERNANDES, M. R. Condições geofísicas para a cafeeicultura. Belo Horizonte, EMATER-MG, 2018.

GHOSH, B. N.; MEENA, V. S.; SINGH, R. J.; ALAM, N. M.; PATRA, S.; BHATTACHARYYA, R.; ... \& MISHRA, P. K. Effects of fertilization on soil aggregation, carbon distribution and carbon management index of maize-wheat rotation in the north-western Indian Himalayas. Ecological Indicators, v. 105, p. 415-424, 2019. Disponível em: https://doi.org/10.1016/j.ecolind.2018.02.050 
GONÇALVES, D. C.; CRESPO, A. M.; FERREIRA, C. C.; CARRICO, I. G. H.; SOUZA, M. N.; RIBEIRO, W. R. A agroecologia como ferramenta ao fortalecimento da agricultura familiar. REVISTA UNIVAP, v.1, p. 342-357, 2019.

HERNANI, L. C., DE FREITAS, P. L., DENARDIN, J. E., KOCHHANN, R. A., DE MARIA, I. C., \& LANDERS, J. N. Uma resposta conservacionista: o impacto do sistema plantio direto. Embrapa Solos-Capítulo em livro técnico (INFOTECA-E). 2002. Disponível em: http://www.infoteca.cnptia.embrapa.br/infoteca/handle/doc/1122029

HERZOG, T. T., SILVA, M. B. D., \& FACCO, A. G. ANÁLISE DO ÍNDICE DE SUSTENTABILIDADE DA PRODUÇÃO DE CAFÉ CONILON. Revista em Agronegócios e Meio Ambiente, v. 13, n. 1, 2020.

LANI, J., TAQUES, R. C., SENRA, J. D. B., \& SOUZA, G. S. Potencial de mecanização das lavouras cafeeiras no Estado do Espírito Santo. 2019.

LAVIOLA, B. G., MARTINEZ, H. E. P., SOUZA, R. B. D., \& ALVAREZ V, V. H. Dinâmica de cálcio e magnésio em folhas e frutos de Coffea arabica. Revista Brasileira de Ciência do Solo, Viçosa , v. 31, n. 2, p. 319-329, Apr. 2007. Disponivel em: https://doi.org/10.1590/\$0100-06832007000200014

LUNZ, A. M. P., BERNARDES, M. S., RIGHI, C. A., COSTA, J. D., FAVARIN, J. L., \& CORTEZ, J. G. Qualidade do café arábica em sistema agroflorestal de seringueira (Hevea brasiliensis Müell. Arg.) e em monocultivo. 2005.

MACHADO, A. H. R., PUIA, J. D., MENEZES, K. C., \& MACHADO, W. A Cultura do Café (Coffeaarabica) em Sistema Agroflorestal. Brazilian Journal of Animal and Environmental Research, v. 3, n. 3, p. 1357-1369, 2020. Disponivel em: https://doi.org/10.34188/bjaerv3n3-053

MANCUSO, M.A.C. Efeito de fontes e doses de potássio na produção, nutrição e exportação de macronutrientes do café arábica. Revista Brasileira de Ciência do Solo. Viçosa, v. 38, n. 5, pág. 1448-1456, outubro de 2014.

MARCATTI, B. A., FRIZZERA JUNIOR, J. L., BURAK, D. L., \& DE SÁ MENDONÇA, E. Qualidade biológica dos solos sob diferentes usos e manejos no assentamento Florestan Fernandes-ES. Cadernos de Agroecologia, v. 15, n. 2, 2020.

MARTINEZ, H. E. P., CleMENTE, J. M., LACERDA, J. S. D., NEVES, Y. P., \& PEDROSA, A. W. Nutrição mineral do cafeeiro e qualidade da bebida. Revista. Ceres, Viçosa, v. 61, supl. p. 838-848, Dec. 2014.

MATTOS JUNIOR, D., MACEDO, L., HIPPLER, F., BOARETTO, R., QUAGGIO, J., \& STIPP, S. Avanços na nutrição de citros e café. Informações Agronômicas, Piracicaba, n. 163, p. 1-11, 2018.

PADOVAN, M. D. P., DE MUNER, L. H., FORNAZIER, M., CAPORAL, F., BRANDO, J., \& RONCA, P. Sustainable Conilon Coffee cultivation. 2019. 
PALOMO-CAMPESINO, S. Explorando as conexões entre as práticas agroecológicas e os serviços ecossistêmicos: uma revisão sistemática da literatura. Sustentabilidade, v. 10, n. 12, pág. 4339, 2018.

PARECIDO, R. J. Nutrição e produtividade da cultura do café arábica afetadas pela forma de aplicação de calcário e gesso na cultura já implantada. Repositório institucional UNESP. 2020.

PEREIRA, M. E. B. G.; LOURENZANI, A. E. B. S.; WATANABE, K. Indicações Geográficas como estratégia de desenvolvimento: o caso do Norte Pioneiro do Paraná. Interações (Campo Grande), Campo Grande , v. 19, n. 3, p. 515-528, Sept. 2018. Available

from $<$ http://old.scielo.br/scielo.php?script=sci_arttext\&pid=S1518-

70122018000300515\&lng=en\&nrm=iso>. access on 13 Aug. 2021. https://doi.org/10.20435/inter.v19i3.1654.

PEREIRA, I. M.; JAEGGI, M. E. P. C.; ROCHA, R. S.; ENTRINGER, G. C.; CRUZ, D. P.; LIMA, W. L.; SOUZA, M. N.; GRAVINA, G. A.; OLIVEIRA, T. R. A.; SANTANNA, C. Q. S. S. Morphological characterization of strains of bean pod promising south capixaba. American International Journal of Agricultural Studies., v.3, n.127, p.14-18, 2020.

PRIORI, A., POMARI, L. R., AMÂNCIO, S. M., \& IPÓLITO, V. K. A cafeicultura no Paraná, histórias do Paraná: séculos XIX e XX [online]. Maringá: Eduem. A cafeicultura no Paraná. pp. 91-104. ISBN 978-85-7628-587-8. 2012. Available from SciELO Books http://books.scielo.org

ROCHA, O. C., GUERRA, A. F., RAMOS, M. L. G., VEIGA, A. D., BARTHOLO, G. F., RODRIGUES, G. C., ... \& SILVA, T. P. D. Relação solo-água em função da brachiaria nas entrelinhas do café no cerrado. Coffee Science, Lavras, v. 9, n. 4, p. 516 - 526, out./dez. 2014.

SANTOS, M. B.; BENTES, A.; RODRIGUES, D. L.; SILVA, G. B.; LIMA, G. M. . Análise da compatibilidade entre o uso do solo e sua capacidade na vertente norte do Córrego do Jacaré, entorno do Parque Estadual de Paraúna, Goiás. In: XII Simpósio Nacional de Geomorfologia - SINAGEO, 2018, Crato. ANAIS DO XII SINAGEO, 2018. https://www.sinageo.org.br/2018/trabalhos/6/6-417-2203.html

SILVA, A. R., DIAS JUNIOR, M. D. S., GUIMARÃES, P. T. G., \& ARAÚJO JÚNIOR, C. F. Modelagem da capacidade de suporte de carga e quantificação dos efeitos das operações mecanizadas em um latossolo amarelo cultivado com cafeeiros. Revista Brasileira de Ciência do Solo, v.30 p.207-216, 2006. Disponível em: https://doi.org/10.1590/S0100-06832006000200002. Acesso em: 21/04/2021

SILVA, R. F.;COSTA SEVERIANO, E., OLIVEIRA, GC, BARBOSA, SM, PEIXOTO, DS, TASSINARI, D., ... \& FIGUEIREDO, TDAFR. Changes in soil profile hydraulic properties and porosity as affected by deep tillage soil preparation and Brachiaria 
grass intercropping in a recent coffee plantation on a naturally dense Inceptisol. Soil and Tillage Research, v. 213, p. 105127, 2021. Disponível em: https://doi.org/10.1016/j.still.2021.105127

SILVA, V. M. D., TEIXEIRA, A. F. R., SOUZA, J. L. D., GUIMARÃES, G. P., BENASSI, A. C., \& MENDONÇA, E. D. S. Estoques de Carbono e Nitrogênio e Densidade do Solo em Sistemas de Adubação Orgânica de Café Conilon. Revista Brasileira de Ciência do Solo. Viçosa, v. 39, n. 5, p. 1436-1444, 2015. Disponível em: https://doi.org/10.1590/01000683rbcs20140520

SIQUEIRA, R. H. D. S., FERREIRA, M. M., ALCÂNTARA, E. N. D., \& CARVALHO, R. C. D. S. Agregação de um latossolo vermelho-amarelo submetido a métodos de controle de plantas invasoras na cultura do café. Revista Brasileira de Ciência do Solo, Viçosa, v. 38, n. 4, p. 1128-1134, 2014.

SOARES, M. D. R., LIMA, A. F. L. D., CAMPOS, M. C. C., MANTOVANELLI, B. C., CUNHA, J. M., OLIVEIRA, I. A. D., \& BRITO FILHO, E. G. D. Variabilidade espacial da estabilidade dos agregados e matéria orgânica do solo em terra preta arqueológica sob pastagem. Gaia Scientia, 2019.

SOUZA, M. N. Degradação Antrópica e Procedimentos de Recuperação Ambiental. Balti, Moldova, Europe: Novas Edições Acadêmicas, 2018, v.1000. 376p.

SOUZA, I. I. DE M.; ARAÚJO, E. DA S.; JAEGGI, M. E. P. C.; SIMÃO, J. B. P.; ROUWS, J. R. C.; SOUZA, M. N. Effect of afforestation of arabica coffee on the physical and sensorial quality of the bean. Journal of Experimental Agriculture International, v. 42, n. 7, p. 133-143, 2019. DOI: 10.9734 / jeai / 2020 / v42i730562

STEFANOSKI, D. C., SANTOS, G. G., MARCHÃO, R. L., PETTER, F. A., \& PACHECO, L. P. Uso e manejo do solo e seus impactos sobre a qualidade física. Revista Brasileira de Engenharia Agrícola e Ambiental v.17, n.12, p.1301-1309, 2013 Campina Grande, PB.

TROLEIS, M. J. B., ROQUE, C. G., BORGES, M. C. R. Z., NOGUERIRA, K. B., \& GOUVEIA, N. A. Estabilidade de agregados e teor de matéria orgânica em um Latossolo Vermelho sob Urochloa brizantha após a aplicação de cama de peru. Revista de Agricultura Neotropical, v. 4, n. 1, p. 83-87, 2017. Disponível em: DOI: https://doi.org/10.32404/rean.v4i1.1267

VILAS BOAS, G. A cafeicultura na região de planejamento sul de minas e no município de nepomuceno, Minas Gerais. Geosaberes Revista de Estudos $\begin{array}{lllll}\text { Geoeducacionais, } & \text { v. } & 11, & \text { p. } & 656-673,\end{array}$ https://doi.org/10.26895/geosaberes.v11i0.972

ZACARIAS, A. J.; SOUZA, M. N. Recuperação de área degradada de monocultura intensiva no estado do Espírito Santo. Revista Univap, v.1, n. 87, p.234-242, 2019 ZAMBOLIM, L. Tecnologias de produção de café com qualidade. Viçosa: UFV, 2001. 648p 